schmitzii) surely ' mortality' in the age group two to five years is a misprint for 'morbidity' (page 389). It is to be hoped that this chapter will be thoroughly revised and brought up to date in the next edition.

It seems a pity that with the new interest in social medicine there is little mention of recent contributions in this field. Surely the epidemiology of noninfective conditions like peptic ulcer, lung cancer, coronary thrombosis and accidents should find a place in a textbook dealing with the public health, which must embrace the aetiology as well as the prevention and control of community disease. However, this book will continue to be a handy compendium for those who must learn about or administer the present-day public health services of this country.

R.C.

\section{AIDS TO INORGANIC CHEMISTRY}

By R. G. Austin, B.Sc., F.R.I.C. 2nd Edition. Pp. $x+469$, with 22 illustrations. London: Baillière, Tindall \& Cox. r953. ros. 6d.

This new edition provides a comprehensive treatment of the elements and their compounds, presented in groups as they occur in the periodic table, with introductory chapters on chemical phenomena, classification and valency, and the addition of a useful account of the constitution of matter, radioactivity and allied subjects.

Treatment of oxidation and reduction in terms of electron transfer is lacking, and a short discussion of electron orbitals would have been welcome in the chapter on valency, even if at the expense of some of the descriptive matter which at times tends to be over-detailed. Preclinical students will profit from the book if used as intended in conjunction with lecture notes.

\section{MODERN TRENDS IN DIAGNOSTIC RADIOLOGY \\ 2nd Series}

Edited by J. W. McLaren, M.A., M.R.C.P., F.F.R., D.M.R.E. Pp. xi + 4I3, with 359 illustrations. London: Butterworth \& Co. 1953. 70 .

The book edited by Dr. McLaren is a symposium consisting of 24 articles of varying length and importance. As a review of progress and trends in diagnostic radiology in recent years the volume is fairly representative. Some of the chapters are indeed excellent but a few are perhaps out of place in a work of this kind. The book reflects the large influence of Scandinavian work on modern radiology; over half the 24 chapters are, in fact, by Scandinavian authors. There is only one contribution from North America (that by Dr. Singleton of Toronto on the colon), but this is one of the best chapters in the book. Much of the Scandinavian work has already appeared as supplements to Acta Radiologica or, as in the case of FrimannDahl's chapter on the acute abdomen, in the form of a monograph. The chapter by Reid and Tutton from Manchester on myelography is excellent, whilst Lindgren's contribution on lumbar aortography is an admirable synopsis of the subject.

In a work of this kind the Editor must always have a difficult problem in deciding what to include and exclude. Inevitably important work has been excluded and many would quarrel with the choice of some of the articles included. On the whole, however, the book presents a balanced picture of modern trends in diagnostic radiology.

The volume will prove of interest to surgeons and physicians as well as to radiologists, and it must emphasize to the former the great importance of radiology in research and diagnosis and the need for expansion of radiological facilities in this country.

The prominence of Scandinavian work is undoubtedly due to the high standards of equipment and staffing enjoyed in those countries, and to the importance attached to radiological departments in hospitals there.

\section{PICTORIAL INTRODUCTION TO NEUROLOGICAL SURGERY}

By G. F. Rowbotham and D. P. Hammersley.

Pp. viii + 108, with 8r illustrations. Edinburgh: E. \& S. Livingstone, Ltd. I953. 2 Is.

Although Mr. Rowbotham agrees that the only place where operative technique can be satisfactorily learnt is the operating theatre, he submits this work following requests from old pupils for a permanent record of his methods.

Whilst it would be wrong to attempt to teach neurosurgery as a whole by illustrations, head in-? juries are common enough and neurosurgical techniques are sufficiently different from those of general surgery for this work to have a useful field.

The first half of the book deals with the operative techniques involved in opening and closing the head, and in achieving haemostasis within the cranium. The second half is devoted to a comprehensive description of the surgical manoevres, both of an emergency and of an elective nature, that may be needed in cases of head injury. These are considered very fully; for example, methods for attacking extradural haematomata in sites other than the more usual one in the temporal fossa are described.

The illustrations are excellent and the text is, on the whole, appropriate. It is felt, however, that certain subjects, such as the anatomy of the scalp and the spread of septic processes throughout the cranium, should be omitted for unless a surgeon is fully conversant with these matters he will not be contemplating this type of work. A few more details concerning anaesthesia might, instead, be of value for only the positioning of anaesthetic apparatus with regard to towelling is given prominence.

Messrs. Livingstone are to be congratulated on this production and on its reasonable cost. It will prove a graceful addition to the bookshelf of the general surgeon who treats cases of head injury. 